\title{
Time Series Analysis of Gamma exposure rates in Gangneung Area
}

\author{
Hohwan Cha, Jaehwa Kim \\ Department of Physics, Gangneung-Wonju National University
}

\section{강릉 지역 공간 감마선량률의 시계열 분석}

\author{
차호환, 김재화 \\ 강릉원주대학교 물리학과
}

\begin{abstract}
In this work, we investigate the statistical properties of gamma exposure rates using well-known analysis methods, such as Autocorrelation Function Analysis(ACF), Rescaled Range Analysis(R/S Analysis), and Detrended Fluctuation Analysis(DFA). Especially, DFA is an important method to reliably detect long-range correlations in non-stationary time series. Our data are measured by Gangneung regional radiation monitoring station over the period of 1998 to 2011. First, we find a crossover indicating two different governing regimes in fluctuations of gamma exposure rates. Within a year, they show a strong long-ranged memory while this property vanishes over the range of time period longer than one year. Second, our finding is very securely supported by a variety of analysis tools. Those tools yield many relevant exponents which satisfies the well known relation between them.
\end{abstract}

Key Words : Fractal, Time series analysis, Gamma exposure rates, ACF, R/S Analysis, DFA

\section{요야}

본 논문은 1998년부터 2011년까지 강릉 지역의 지방 방사능 측정소에서 측정된 공간 감마선량률의 통계 적인 성질 을 조사하였다. Autocorrelation Function Analysis(ACF), Rescaled Range Analysis(R/S Analysis), Detrended Fluctuation Analysis(DFA)의 방법들이 사용되었으며, 이 중 DFA는 non-stationary한 시계열의 장거리 상관성을 보 여주는 좋은 방법으로 알려져 있다. 우리는 이 연구를 통해 다음의 사실을 알았다. 첫 번째, 공간 감마선량률은 두 가지 다른 경향을 갖는 크로스 오버가 나타난다. 이것은 연중 공간 감마선량률은 강한 장기 기억 특성이 나타나는데 비해 연간으로 넘어가면 상관성이 사라지는 것을 의미한다. 두 번째, 각 분석 방법들의 지수들이 있는데 이 지수들 사이의 관계식이 맞음을 확인 하였다.

중심단어 : 프랙탈, 시계열 분석, 공간 감마선량률, $\mathrm{ACF}, \mathrm{R} / \mathrm{S}$ Analysis, $\mathrm{DFA}$ 


\section{I. 서론}

최근까지 시계열 분석은 물리학, 지구 물리학, 생물 학, 의학, 생리학, 사회학, 및 공학 등의 분야에서 여러 통계적인 분석법에 의해 다양한 특성들을 검증하고자 하는 연구들이 지속적이며 넓게 이루어져 왔으며, 온도, 강수량, 풍속, 구름, 식생 분포 등의 자연 현상에 관한 연구들은 매우 흥미롭다 ${ }^{[1-5]}$. 그러나 지금까지 이런 자 연 현상에 관한 연구가 매우 많이 이루어졌음에도 불구 하고 자연 방사능에 관한 시계열 분석에 대한 연구는 아직까지 많이 이루어지지 않았다. 따라서 시계열 분석 법을 자연 방사능 데이터에 적용하여 그 특성들에 관하 여 분석하는 것은 의미 있는 연구라 할 수 있다.

프랙탈 구조로서의 시계열 분석은 Benoit B. Mandelbrot ${ }^{[6-8]}$ 에 힘 입은 바가 크며, H. E. Hurs ${ }^{[9,10]}$ 에 의해 제안된 허스트 지수를 구함으로서 상관 관계를 설명할 수 있다. 많은 자연 현상의 시계열 데이터들이 Fractional Brownian motion처럼 자기 유사성을 보이는 프랙탈이라는 것은 오래전부터 연구되어 이미 잘 알 려진 사실이다. 불규칙성을 보이는 시계열 데이터들을 통계적으로 설명하기 위한 많은 분석법들이 있다. 이 논문에서는 자주 쓰이는 Autocorrelation Function Analysis(ACF) ${ }^{[11,12]}$, Rescaled Range Analysis(R/S Analysis $)^{[1,6,7,9,10]}$, Detrended Fluctuation Analysis(DFA) [11,13-16] 의 세 가지 방법을 소개하고, 이 방법들을 통하 여 공간 감마선량률의 시계열 데이터를 분석한다.

\section{II. 대상 및 방법}

\section{1. 분석 대상}

본 논문의 분석 대상은 강원도 강릉시 강릉원주 대 학교에 위치한 강릉 지방 방사능 측정소에서 1998년부 터 2011년까지 오전 10시, 오후 4시에 관측한 공감 감 마선량률 데이터이다. 공간 감마선량률 데이터는 한 시간 누적 평균값을 사용하였으며(단위, 마이크로 뢴 트겐, $\mu R / h)$ 지상으로부터 $1 \sim 1.2 \mathrm{~m}$ 높이에 설치된 공 간 감마선량률 감시기를 통하여 주기적으로 측정되었 다.

\section{2. 분석 방법}

강릉 지역 공간 감마선량률 시계열 데이터를 $\mathrm{ACF}$, R/S Analysis, DFA의 세 가지 방법에 대하여 MATLAB 프로그램을 이용하여 코딩하였다. 나온 결과값들은 그 래프 상의 점으로 나타내었으며 이 그래프의 추세선 을 이용하여 각 지수를 구할 수 있다. 이 지수들을 바 탕으로 통계 성질을 분석 하였다.

\section{$2.1 \mathrm{ACF}$}

$\mathrm{ACF}$ 는 시계열 데이터의 상관 관계를 보는 분석 방 법이며 장거리 상관 관계가 있는 경우 다음 식의 지수 를 구하여 그 특징을 알 수 있다.

$$
C(s) \sim s^{-\gamma}
$$

MATLAB 패키지를 통하여 기울기의 지수 값을 알 수 있다.

\section{$2.2 \mathrm{R} / \mathrm{S}$ Analysis}

Edwin Hurst는 수문학 기사인데, 나일강의 댐을 디 자인하다가 Rescaled Range Analysis라는 새로운 통계적 방법을 고안하게 되었다.

$$
Y(i)=\sum_{k=1}^{i}\left[x_{k}-<x>\right] \quad i=1, \ldots \ldots, N \cdots \cdots \cdots
$$

여기서 $x_{k}$ 는 시계열의 기록 값들이며, $\langle x>$ 는 기 록 값의 평균이고, $Y(i)$ 는 누적 값이다. 다음 단계는 누적 값 $Y(i)$ 의 최대값과 최소값의 차이를 나타내는 것이다.

$$
R(s)=\max Y(i)-\min Y(i)
$$

이 차이가 Range R이며, $s$ 는 전체 데이터를 나누는 임의의 개수이다. 마지막으로 표준 편차를 구한다.

$$
S(s)=\sqrt{\frac{1}{s} \sum_{i=1}^{s} Y^{2}(i)}
$$

임의의 $s$ 에 대한 $R / S$ 의 값을 MATLAB 프로그램 수치 해석으로 구할 수 있다. 


\subsection{DFA}

$\mathrm{DFA}$ 는 Peng et $\mathrm{al}^{[13]}$ 에 의해 제안되었으며, non-stationary한 시계열에서 프랙탈의 특성을 결정하기 위 하여 폭넓게 사용되어 왔다.

$$
Y(i)=\sum_{k=1}^{i}\left[x_{k}-<x>\right] \quad i=1, \ldots \ldots, N \cdots \cdots
$$

여기서 $x_{k}$ 는 시계열의 기록 값들이며, $\langle x>$ 는 평 균이고, $Y(i)$ 는 누적 값이다. $Y(i)$ 의 값에서 최소 자 승법, $y_{\nu}(i)$ 으로 구한 식을 빼는 것으로 중간 단계의 결과를 얻을 수 있고 그 식은 다음과 같다.

$$
F^{2}(s, \nu)=\frac{1}{s} \sum_{i=1}^{s}\left\{Y[(\nu-1) s+i]-y_{\nu}(i)\right\}^{2}
$$

여기서 $s$ 는 전체 데이터를 나누는 임의의 개수이 고, $\nu=1, \ldots \ldots, N_{s}$ 이며, $N_{s}=N / s$ 이다.

하지만 전체 시계열 데이터들이 항상 $s$ 로 나누어지 는 것은 아니므로, 데이터의 활용도를 높이기 위하여 데이터 값의 대입 순서를 정반대의 값으로부터 위의 식을 반복하여 실행함으로써 끝 부분에 남은 기록 값 들도 분석할 수가 있다.

$F^{2}(s, \nu)=\frac{1}{s} \sum_{i=1}^{s}\left\{Y\left[N-\left(\nu-N_{s}\right) s+i\right]-y_{\nu}(i)\right\}^{2}$

여기서 $\nu=N_{s}+1, N_{s}+2, \ldots \ldots, 2 N_{s}$ 이다.

이 과정의 마지막 단계는 앞의 식을 이용하여 산출 한 결과들의 평균을 구하는 것이다. 그리고 제곱근을 취함으로서 다음과 같이 식을 얻는다.

$$
F(s)=\left[\frac{1}{2 N_{s}} \sum_{\nu=1}^{2 N_{s}} F^{2}(s, \nu)\right]^{1 / 2} \sim s^{\alpha}
$$

이 식을 $s$ 의 값을 다르게 계산하여 각각의 $F(s)$ 를 구하고, $F(s)$ 와 $s$ 의 값을 MATLAB 프로그램 수치 해 석으로 구할 수 있다.

\section{III. 결과 및 고찰}

이 장에서는 위의 세 가지 분석 방법을 MATLAB 프로그램에 적용하여 나온 결과를 그래프에 그리고 기울기를 이용하여 결과 및 고찰을 한다.

먼저 ACF 방법을 이용하여 분석하였으며, Fig. 1에 서 보듯이 (a)오전, (b)오후의 지수는 각각 $\gamma=0.25$, $\gamma=0.26$ 이다. 기울기가 $0<\gamma<1$ 의 값을 갖는다는 것 은 분석된 시계열 데이터가 자기 유사성을 갖고 있으 며 Long range correlation의 특성을 갖는 것으로 분석 할 수 있다.

다음으로 R/S Analysis 방법과 DFA 방법을 적용하여 결과를 분석한다. Fig. 2은 R/S Analysis 방법의 결과를 나타내며 (a)오전, (b)오후가 $\log 2.5$ 근처에서 크로스 오 버를 보임을 알 수 있다. 크로스 오버 이전과 이후의 지수는 오전이 각각 $H=0.79, H=0.60$ 이며 크로 스 오버 이전은 Persistence한 특성을 갖는 것으로, 이후 로는 Brownian motion에 가까워지는 것을 알 수 있다.

(a)

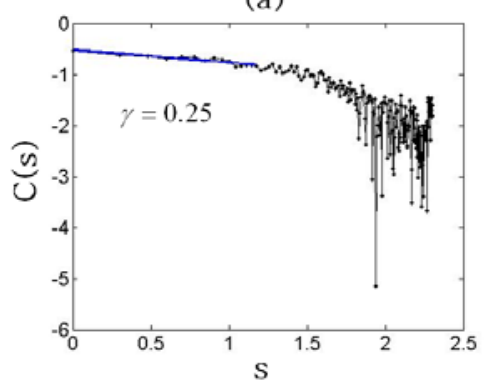

(b)

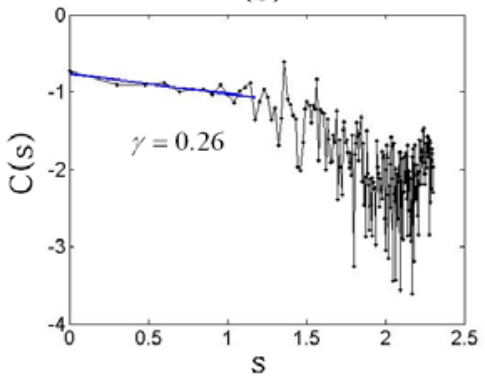

Fig. 1. Autocorrelation Function Analysis for time series data of gamma exposure rates at morning and afternoon. Which showed exponent (a) $\gamma=0.25$, (b) $\gamma=0.26$ 
(a)

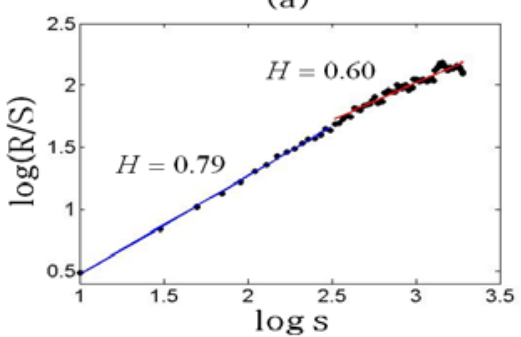

(b)

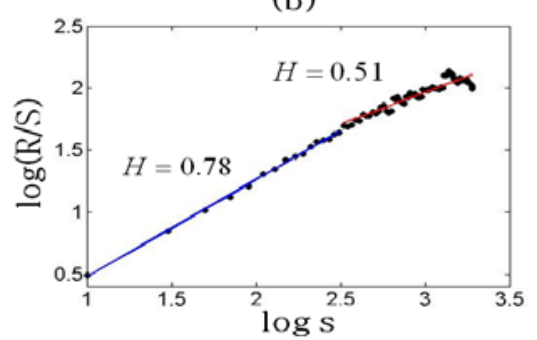

Fig. 2. R/S Analysis for time series data of gamma exposure rates at morning and afternoon. Which showed exponent (a)blue line(before crossover) $H=0.79$ and red line(after crossover) $H=0.60$, (b)blue line(before crossover) $H=0.78$ and red line(after crossover) $H=0.51$.

(a)

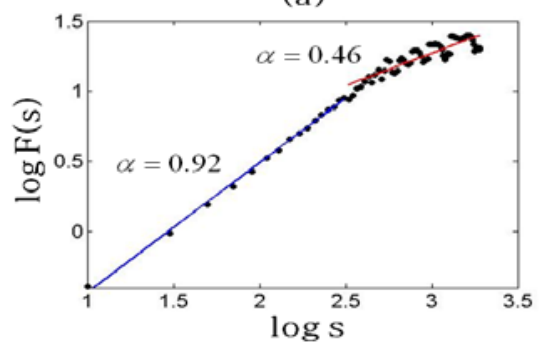

(b)

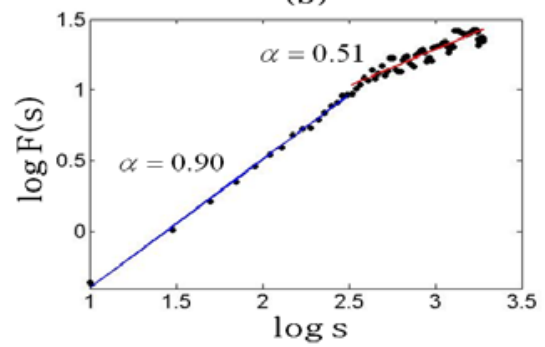

Fig. 3. Detrended Fluctuation Analysis for time series data of gamma exposure rates at morning and afternoon. Which showed exponent (a)blue line(before crossover) $\alpha=0.92$ and red line(after crossover) $\alpha=0.46$, (b)blue line(before crossover) and $\alpha=0.90$ red line(after crossover)

$$
\alpha=0.51 \text {. }
$$

오후의 지수값은 $H=0.78, H=0.51$ 이며 크로스 오버 이전은 Persistence한 특성을 갖는 것으로, 크로스 오버 이후의 값이 Brownian motion임을 알 수 있다.

Fig 3.은 DFA 방법의 결과를 나타내며 (a)오전, (b)오 후가 $\log 2.5$ 근처에서 크로스 오버가 나타남을 알 수 있다. 크로스 오버 이전과 이후의 지수는 오전이 각각 $\alpha=0.92, \alpha=0.46$ 이며 크로스 오버 이전은 Long range correlation한 특성을 갖는 것으로, 이후로는 Anti correlation의 특성을 갖는 것을 알 수 있다. 오후의 크 로스 오버 이전과 이후의 지수값은 $\alpha=0.90$, $\alpha=0.51$ 이며 크로스 오버 이전은 Long range correlation한 특성을 갖는 것으로, 이후로는 White noise 의 특성을 갖는 것을 알 수 있다.

(a)

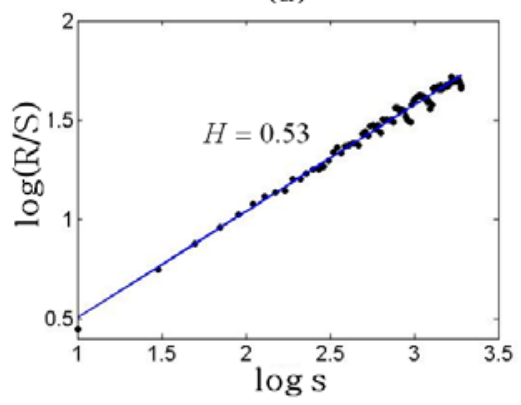

(b)

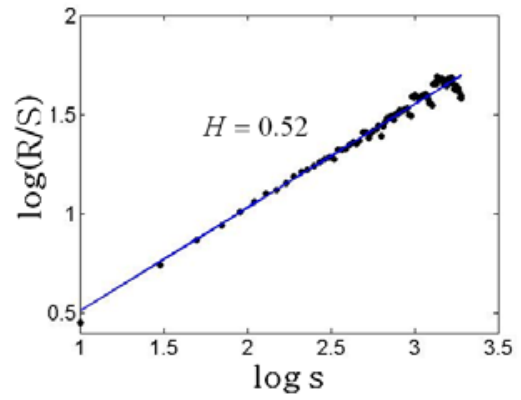

(c)

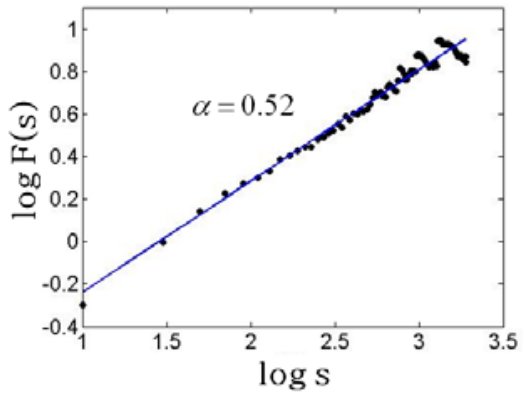


(d)

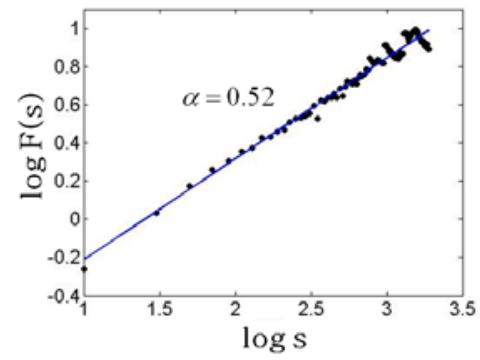

Fig. 4. R/S Analysis and Detrended Fluctuation Analysis for shuffled time series data of gamma exposure rates at morning and afternoon. Which showed exponent (a) $H=0.53$, (b) $H=0.52$, (c) $\alpha=0.52$, (d) $\alpha=0.52$.

R/S Analysis 방법과 DFA 방법은 비슷한 지수 값 결 과가 나왔으며 각 지수들의 관계도 큰 오차를 보이지 않고 만족함을 알 수 있다.

R/S Analysis와 DFA 방법의 오전, 오후 값을 비교해 보면 같은 분석 방법의 오전, 오후 그래프가 거의 일 치함을 알 수 있다. 이것은 강릉 지방 공간 감마선량 이 태양의 영향을 받지 않는 것으로 분석 된다.

마지막으로 RS Analysis, DFA 방법으로 데이터를 셔플링하여 분석하였다. Fig. 4 와 같이 지수가 상관성 이 사라지는 값인 0.5 에 가깝게 나왔다. 이 결과를 통 하여 원래의 시계열 데이터만이 상관성이 있다는 것 을 검증하였다.

시계열 분석 방법은 현재 국내에서도 수문학 ${ }^{[17]}$, 금 융학 ${ }^{[18]}$, 수면 뇌파분석 ${ }^{[19,20,21]}$, 운동역학 ${ }^{[22]}$ 등 여러 분 야의 연구에 이용 되고 있다.

본 논문에서도 세 가지 분석 방법을 통하여 분석한 결과 다른 현상들에 관한 연구와 마찬가지로 공간 감 마선량률은 연중에 관하여 Long range correlation한 특 성을 갖는 것을 알 수 있다.

현재 많은 분야에 시계열 데이터가 존재하며 이 데 이터들은 본 논문의 분석 방법을 이용하여 연구 되고 있다. 뇌파 분석을 통해 수면단계 분석과 수면장애등 의 현상을 분석하는 것에 대한 연구는 이미 많이 알려 진 연구 예이다. ${ }^{[20]}$ 시계열 분석을 통하여 알아낸 통계 성질을 이용하여 여러 복잡해 보이는 현상들의 상관 성을 분석하는 것이다. 방사선 분야 또한 많은 시계열
데이터가 존재하며 다양한 연구에 적용이 가능할 것 으로 사료된다. 따라서 학문간 공동 연구가 이루어질 수 있도록 각 분야의 연구자들이 활발하고 지속적인 논의를 해야 할 것이다.

\section{IV. 결론}

강릉 지역 공간 감마선량률은 오전, 오후 모두 $\log 2.5$, 약 320 일을 중심으로 두 가지 다른 경향을 갖는 크로스 오버가 나타난다. 따라서 강릉 지방의 공간 감 마선량률은 연중에 대해선 강한 Long range correlation 특성을 갖는 것으로, 연간에 대해선 상관성이 사라지 는 Brownian motion의 특성을 갖는 것으로 결론을 내 릴 수 있다. 또한 각 분석 방법들로 Persistence한 특성 을 갖는 부분의 지수들을 구하였고, 이 지수들 사이의 관계식이 맞음을 확인 하였다.

시계열 분석에 있어서 가장 큰 난관은 시계열 데이 터의 확보이다. 그 결과 본 논문에서는 강릉 지역만을 제한적으로 분석 하였다. 앞으로 관계 기관과 협조하 여 전국 12 개 지역의 지방 방사능 측정소와 59 개의 간 이 방사능 측정소에서 수집된 공간 감마선량률에 관한 시계열 분석을 하여 각 지방의 통계적 특성을 비교 분 석 할 필요가 있다고 사료되며 더 나가서는 다른 자연 방사능 시계열 데이터에도 적용해 보아야 할 것이다.

시계열 분석은 현재 많은 분야의 연구에 이용 되고 있다. 특히 최근에는 수면 뇌파 분석 ${ }^{[19,20,21]}$ 분야에서 많이 연구되고 있으며 심장 박동 분석 ${ }^{[23]}$ 과 같은 의학 분야나 방사선 분야의 연구에도 이용될 수 있을 것으 로 사료된다.

\section{참고문헌}

[1] J. Feder, Fractals, Plenum Press, New York, 1988.

[2] M.F. Barnsley, Fractals everywhere, Academic Press, 1993.

[3] P.E.T. Jorgenssen, Analysis and probability: wavelets, signals, fractals, Springer, Berlin 2000.

[4] A. Bunde, J. Kropp, H.-J. Schellnhuber, The science of disasters climate disruptions, heart attacks, and market crashes, Springer, Berlin 2002.

[5] H. Kantz, T. Schreiber, Nonlinear time series analysis, Cambridge University Press, 2003. 
[6] B.B. Mandelbrot, J.W. van Ness, Fractional Brownian motions, fractional noises and applications, SIAM Review, Vol.10, No.422, 1968 .

[7] B.B. Mandelbrot, J.R. Wallis, Some long-run properties of geophysical records, Water Resour. Res. vol.5, p.321-340, 1969.

[8] Benoit B. Mandelbrot, Multifractals and 1/f noise: wild self-affinity in physics, Springer, Berlin 1999.

[9] H.E. Hurst, Long-term storage capacity of reservoirs, Transactions of the American Society of Civil Engineering, Vol.116, No.770, 1951.

[10] H.E. Hurst, R.P. Black, Y.M. Simaika, Long-term storage: an experimental study, Constable and Co, Ltd, London, 1965.

[11] M.S. Taqqu, V. Teverovsky, W. Willinger, Estimators for long-range dependence: An empirical study, Fractals, Vol.3, No.785, 1995.

[12] G.A. Hunt, Random Fourier transforms, Trans. Amer. Math. Soc. Vol.71, No.38, 1951.

[13] C.-K. Peng, S.V. Buldyrev, S. Havlin, M. Simons, H.E. Stanley, A.L. Goldberger, Mosaic organization of DNA nucleotides, Phys. Rev. E, Vol.49, No.1685, 1994.

[14] J. Mielniczuk, P. Wojdyllo, Estimation of Hurst exponent revisited, Comp. Stat. Data. Anal. Vol.51, No.4510, 2007.

[15] C. Heneghan, G. McDarby, Establishing the relation between detrended uctuation analysis and power spectral density analysis for stochastic processes, Phys. Rev. E, Vol.62, No.6103, 2000.

[16] R. Weron, Estimating long-range dependence: nite sample properties and condence intervals, Physica A, Vol.312, No.285, 2002.

[17] 김병식, 김형수, 서병하 : 허스트 지수 산정 방법에 대한 고찰, 한국수자원학회논문지, Vol.37, No.12, p.993 1007, 2004.

[18] 오갑진, 엄철준, 김승환외 1 명 : 주식 가격 변화의 장기 기억속성 존재 및 영향요인에 대한 실증 연구, 금융공학연구, Vol.3, No.24, p.63 89, 2007.

[19] 신홍범, 정도언, 김의중 : 정상인 수면 뇌파 탈경향변동분석, Sleep Medicine and Psychophysiology, Vol.14, No.1, p.42 48, 2007.

[20] 김종원 : 컴퓨터를 이용한 수면 뇌파 분석 스펙트럼, 비경향 변동, 동기화 분석 예시, Sleep Medicine and Psychophysiology, Vol.15, No.1, p.5 11, 2008.

[21] 예수영, 백승완 : 뇌파신호의 DFA 분석을 이용한 마취심도 측정, 한국산학기술학회논문지, Vol.11, No.7, p.2491 2496, 2010.
[22] 최승진, 강동원, 탁계래 : 보행속도변화와 동시 인지과제가 보행 가변성에 미치는 영향, 한국운동역학회지, Vol.18, No.2, p.49 58, 2008.

[23] Y. Ashkenazy, P. Ch. Ivanov, S. Havlin, C.-K. Peng, A. L. Goldberger, H. E. Stanley, Magnitude and sign correlation in heartbeat fluctuations, Phys. Rev. Lett. Vol.86, No.1900, 2001. 